\title{
PENGARUH PERSONAL SELLING, KUALITAS PRODUK TERHADAP KEPUTUSAN PEMBELIAN MELALUI KEPUASAN KONSUMEN DI TOKO BAGIAK PELANGI SARI BANYUWANGI
}

Oleh :

\section{DRIYANTO WAHYU WICAKSONO *), BAGUS PUTU YUDHIA K dan HARIADI SUBAGJA **)}

\begin{abstract}
ABSTRAK
Kompetisi menjadi keniscayaan dalam setiap persoalan bisnis. Hal ini dapat dilihat dengan munculnya pelaku bisnis baru. Begitupun juga yang dihadapi oleh pengusaha bagiak yang ada di Banyuwangi, tidak luput juga Toko Kue Bagiak Pelangi Sari Banyuwangi. Tujuan penelitian ini adalah untuk mengetahui pengaruh langsung dan tidak langsung personal selling, kualitas produk terhadap keputusan pembelian melalui kepuasan konsumen. Populasi penelitian adalah konsumen yang membeli kue bagiak pelangi sari Banyuwangi. Jumlah sampel 85 responden dengan accidental sampling. Data diperoleh dengan kuesioner. Analisis data dengan deskriptif persentatif yaitu persentasi dan path analysis. Hasil penelitian ini menunjukkan bahwa variabel personal selling $\left(X_{1}\right)$, kualitas produk $\left(X_{2}\right)$ berpengaruh langsung terhadap keputusan pembelian. Variabel personal selling $\left(\mathrm{X}_{1}\right)$, kualitas produk $\left(\mathrm{X}_{2}\right)$ tidak berpengaruh langsung terhadap keputusan pembelian. Hasil dari uji path analysis menunjukkan bahwa personal selling $\left(\mathrm{X}_{1}\right)$ berpengaruh terhadap keputusan pembelian (Y) melalui kepuasan konsumen $(\mathrm{Z})$ dan kualitas produk $\left(\mathrm{X}_{2}\right)$ berpengaruh langsung terhadap keputusan pembelian (Y) melalui kepuasan konsumen $(\mathrm{Z})$, sehingga dapat dikatakan bahwa kepuasan konsumen $(\mathrm{Z})$ memediasi pengaruh personal selling $\left(\mathrm{X}_{1}\right)$ dan kualitas produk $\left(\mathrm{X}_{2}\right)$ terhadap keputusan pembelian (Y).
\end{abstract}

Kata kunci : selling, kualitas produk, kepuasan ,konsumen

\section{PENDAHULUAN}

Tetapi saat ini perkembangan dunia bisnis di khususnya Banyuwangi semakin pesat.Hal ini dapat dilihat dengan munculnya pengusahapengusaha atau pelaku bisnis yang baru.Persaingan bisnis yang ketat seperti saat ini membuat pelaku bisnis selalu berusaha untuk mempertahankan usahanya dan bersaing untuk mencapai tujuan yang diharapkan.Pertumbuhan yang selalu meningkat dari waktu ke waktu selalu diharapkan oleh pelaku bisnis.

Berbagai cara dilakukan oleh pelaku bisnis agar usaha yang dijalankan tetap bertahan di tengah-tengah persaingan yang ada. Suatu usaha didirikan dan dikelola untuk menghasilkan suatu produk, baik berupa barang maupun jasa. Produk itu dipasarkan dan dijual kepada pihak lain, baik individu, maupun kelompok, yang memerlukan produk itu untuk memenuhi sebagian kebutuhannya.

Mereka harus mampu memenuhi kebutuhan konsumen, karena tidak bisa dipungkiri bahwa konsumen merupakan sumber profit mereka.memilih pemasaran yang baik dalam menjalankan suatu usaha merupakan cara yang tepat agar tetap eksis dalam persaingan dan produknya bisa dikenal dan diminati konsumen.
Tabel 1

Penjualan Bagiak Pelangi Sari Banyuwangi Desember Tahun 2014

\begin{tabular}{|c|c|c|c|c|c|}
\hline Bulan & $\begin{array}{c}\text { Bagiak } \\
\text { dus }\end{array}$ & $\begin{array}{c}\text { Bagiak } \\
\text { Jagung }\end{array}$ & $\begin{array}{c}\text { Bagia } \\
\mathbf{k} \\
\text { Unyil }\end{array}$ & $\begin{array}{c}\text { Bagia } \\
\mathbf{k} \\
\text { Mika } \\
\text { mini }\end{array}$ & $\begin{array}{c}\text { Jumla } \\
\mathbf{h} \\
\text { Kema } \\
\text { san }\end{array}$ \\
\hline Jan & 1.772 & 1.995 & 2.100 & 600 & 6.467 \\
\hline Peb & 1.297 & 2.292 & 2.140 & 624 & 6.353 \\
\hline Mar & 1.959 & 1.379 & 2.025 & 520 & 5.883 \\
\hline Apr & 1.916 & 1.712 & 1.870 & 342 & 5.840 \\
\hline Mei & 1.723 & 1.611 & 1.800 & 450 & 5.584 \\
\hline Jun & 2.200 & 2.207 & 2.220 & 345 & 6.972 \\
\hline Jul & 2.650 & 2.856 & 2.800 & 700 & 9.006 \\
\hline Agst & 1.574 & 2.301 & 2.430 & 345 & 6.650 \\
\hline Sept & 1.958 & 2.300 & 2.220 & 460 & 6.938 \\
\hline Okt & 2.150 & 2.410 & 2.340 & 475 & 7.375 \\
\hline Nop & 2.351 & 2.529 & 2.650 & 500 & 8.030 \\
\hline Des & 2.560 & 2.710 & 2.800 & 650 & 8.720 \\
\hline Total & 24.110 & 26.302 & 27.39 & 6.011 & 83.818 \\
\hline $\begin{array}{c}\text { Rata- } \\
\text { rata/bu } \\
\text { lan }\end{array}$ & $\mathbf{2 . 0 0 9}$ & $\mathbf{2 . 1 9 2}$ & $\mathbf{2 . 2 8 3}$ & $\mathbf{5 0 1}$ & $\mathbf{6 . 9 8 5}$ \\
\hline
\end{tabular}

Sumber:Data Primer yang telah diolah 
Gambar1

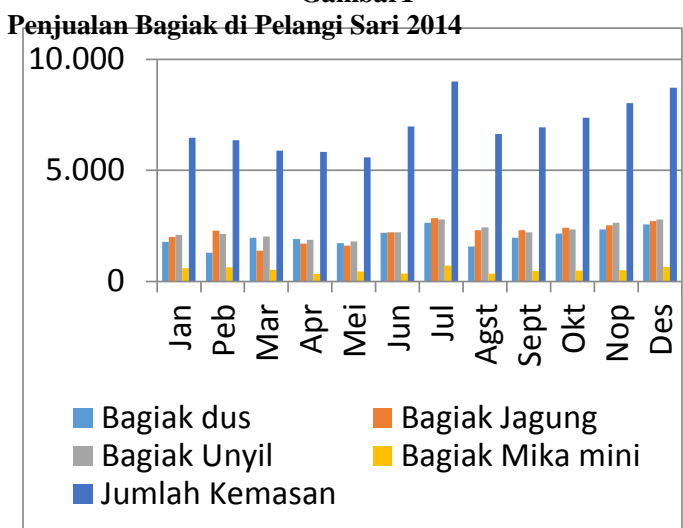

Sumber:Data Primer yang telah diolah

Data penjualan tersebut didapatkan total produk Bagiak Pelangi sari yang terjual selama tahun 2014 adalah sebanyak 83.818 kemasan, dan rata-rata perbulan adalah sebanyak 6.985 kemasan yang terjual.

Pada tahun 2014 kegiatan mudik sebelum lebaran padat dibulan Juli, dimana pada data penjualan bagiak pelangi sari meningkat hingga 9.006 kemasan selama 1 bulan.Dalam hal ini semakin menunjukkan bahwa intensitas masyarakat Banyuwangi banyak mayoritas muslim yang hendak melakukan kegiatan hari raya idul fitri dan bersilaturahmi kepada orang lain berpengaruh terhadap penjualan dan pemasaran kue bagiak yang meningkat jauh dan dimana proses kepuasan konsumen tersebut dapat terjadi.

Berdasarkan fenomena bisnis dan kajian empiris yang diuraikan di atas, peneliti merasa perlu untuk mengetahui adanya pengaruh Personal Selling dan Kualitas Produk dalam membentuk sebuah kepuasan konsumen tersebut mampu mempengaruhi keputusan konsumen untuk membeli pusat oleh-oleh khas, Dalam hal ini peneliti, mengambil dengan judul “ Pengaruh Personal Selling, Kualitas Produk Terhadap Keputusan Pembelian Kue Bagiak Pelangi Sari Banyuwangi Melalui Kepuasan Konsumen”.

\section{Perumusan Masalah}

Berdasarkan uraian diatas, maka yang menjadi permasalahan pokok dalam penelitian ini adalah:

1. Apakah Personal Selling berpengaruh signifikan terhadap kepuasan konsumen toko kue bagiak pelangi sari Banyuwangi?

2. Apakah kualitas produk berpengaruh signifikan terhadap kepuasan konsumen di toko kue bagiak pelangi sari Banyuwangi?

3. Apakah Personal Selling berpengaruh signifikan terhadap keputusan pembelian di toko kue bagiak pelangi sari Banyuwangi?
4. Apakah kualitas produk berpengaruh signifikan terhadap keputusan pembelian di toko kue bagiak pelangi sari Banyuwangi?

5. Apakah kepuasan konsumen berpengaruh signifikan terhadap keputusan pembelian di toko kue bagiak pelangi sari Banyuwangi?

\section{Tujuan Penelitan}

Berdasarkan rumusan masalah diatas, maka tujuan dari penelitian ini adalah untuk:

1. Untuk menganalisis dan menguji pengaruh Personal Selling terhadap kepuasan konsumen di toko kue bagiak pelangi sari Banyuwangi.

2. Untuk menganalisis dan menguji pengaruhkualitas produk terhadap kepuasan konsumen di toko kue bagiak pelangi sari Banyuwangi.

3. Untuk menganalisis dan menguji pengaruh Personal Selling terhadap Keputusan pembelian di toko kue bagiak pelangi sari Banyuwangi.

4. Untuk menganalisis dan menguji pengaruh kualitas produk terhadap keputusan pembelian di toko kue bagiak pelangi sari Banyuwangi.

5. Untuk menganalisis dan menguji pengaruh kepuasan konsumen terhadap keputusan pembelian di toko kue bagiak pelangi sari Banyuwangi.+

\section{Manfaat Penelitian}

Penelitian ini diharapkan dapat bermanfaat bagi semua pihak, antara lain :

1. Bagi Peneliti

Sebagai pengalaman yang berharga dalam menambah pengalaman dan pengetahuan, serta diharapkan dapat menjadi bahan acuan bagi penelitian selanjutnya.

2. Bagi perusahaan

Penelitian ini diharapkan bisa menjadi bahan pertimbangan dan masukan bagi toko kue bagiak pelangi sari selaku produsen produk pusat oleh-oleh khas untuk menetapkan kebijakan dan strategi yang menyangkut Personal selling, kualitas produk terhadap keputusan pembelian melalui kepuasan konsumen.

3. Bagi Akademis

Sebagai referensi kepustakaan dalam memberikan informasi dan kontribusi bagi pengembangan ilmu pengetahuan di bidang manajemen pemasaran.

\section{KAJIAN PUSTAKA}

Salah satu unsur pemasaran adalah personal selling, Penerapan Personal Selling yang tepat dalam perusahaan akan memberikan kontribusi atau manfaat yang besar dalam memasarkan suatu 
produk. Adapun indikator yang terdapat dalam proses personal selling menurut Kotler dan Amstrong dalam Tarihoran (2010) adalah Pendekatan (Approach), Presentasi (Presentation), Mengatasi keberatan (Handing Objection), Menutup Penjualan (Closing)

Sedangkan kualitas produk merupakan salah satu unsur penting dari keunggulan produk sangat ditentukan oleh keunikan produk, inovasi produk yang terus menerus, kemampuan produk untuk memenuhi kebutuhan konsumen, kemampuan produk mereduksi biaya yang dikeluarkan konsumen, kecanggihan produk, dan desain produk itu sendiri.Gaspersz (2008) menjelaskan bahwa dimensi dari kualitas produk ini meliputi 7 indikator, yang terdiri dari :

1. Kinerja (performance) yaitu sebuah produk merupakan pencerminan bagaimana sebuah produk itu disajikan atau ditampilkan kepada konsumen bagiak pelangi sari.

2. keistimewaan tambahan (features) yaitu sebagai tingkat kelengkapan atribut-atribut yang ada pada sebuah produk bagiak pelangi sari

3. kesesuaian dengan spesifikasi (conformance to specifications) yaitu sebagai tingkat dimana semua unit yang diproduksi identik dan memenuhi spesifkasi sasaran yang dijanjikan oleh produsen bagiak pelangi sari.

4. daya tahan (durability) yaitu berkaitan dengan berapa lama produk tersebut dapat terus digunakan konsumen bagiak pelangi sari

5. perbaikan (service ability) yaitu sebagai suatu ukuran kemudahan memperbaiki suatu produk bagiak pelangi sari yang rusak atau gagal.

6. keindahan produk (Aesthethics) yaitu sebagai atribut-atribut yang melekat pada sebuah produk, seperti warna, model atau desain, bentuk, rasa, aroma bagiak pelangi sari

7. kualitas yang dipersepsikan (perceived quality) yaitu kualitas yang dirasakan oleh konsumen bagiak pelangi sari

Kotler dan Amstrong (2001) berpendapat bahwa kepuasan konsumen menunjukkan sejauh mana kinerja yang diberikan oleh sebuah produk sepadan dengan harapan pembeli. Kepuasan Konsumen menurut Tjiptono (2006:41), Kepuasan konsumen dipengaruhi dua variabel utama, yaitu Expectations dan Perceived

Performance, bila Perceived Performance melebihi Expectations, maka konsumen mendapatkan kepuasan, akhirnya akan menciptakan loyalitas konsumen. Indikator Kepuasan Konsumen ialah :

a) Overall Satisfacation

Tingkat kepuasan pelanggan secara keseluruhan. b) Expectation
Kesesuaian produk dan/atau pelayanan yang ditawarkan dengan harapan pelanggan.

c) Experience

Tingkat kepuasan pelanggan selama menjalin hubungan dengan perusahaan.

Menurut Peter dan Olson (1999), "Keputusan pembelian adalah proses pengintegrasian yang mengkombinasikan pengetahuan untuk mengevaluasi dua atau lebih perilaku alternatif dan memilih salah satu diantaranya".

Kualitas dari produk itu sendiri dapat menarik konsumen untuk mencoba dan kemudian akan mengambil keputusan untuk membeli produk tersebut. Menurut Haubl (2007) Indikator untuk keputusan pembelian, yaitu :

1) Daya tarik, yaitu kelebihan-kelebihan kue bagiak pelangi sari yang membuat konsumen terpacu untuk membeli.

2) Kemantapan atau keyakinan membeli, yaitu keadaan dimana konsumen benar-benar yakin untuk mengambil keputusan dalam memilih kue bagiak pelangi sari.

3) Sesuai kebutuhan, yaitu mampu memenuhi kebutuhan konsumen.

Berdasarkan uraian diatas dapat disusun hipotesis penelitian sebagai berikut :

$$
\begin{aligned}
& \mathbf{H}_{\mathbf{1}} \text { : Terdapat pengaruh yang } \\
& \text { signifikan antara variabel } \\
& \text { Personal Selling, terhadap } \\
& \text { Kepuasan Konsumen. } \\
& \mathbf{H}_{2} \text { : Terdapat pengaruh yang } \\
& \text { siginifikan antara variabel } \\
& \text { Kualitas Produk terhadap } \\
& \text { Kepuasan Konsumen. } \\
& \mathbf{H}_{3} \text { : Terdapat pengaruh yang } \\
& \text { signifikan antara variabel } \\
& \text { Kepuasan konsumen terhadap } \\
& \text { Keputusan Pembelian . } \\
& \mathbf{H}_{4} \text { : Terdapat pengaruh yang } \\
& \text { signifikan antara variabel } \\
& \text { Personal Selling terhadap } \\
& \text { Keputusan Pembelian. } \\
& \mathbf{H}_{5} \text { : Terdapat pengaruh yang } \\
& \text { signifikan antara variabel } \\
& \text { Kualitas Produk terhadap } \\
& \text { Keputusan Pembelian. }
\end{aligned}
$$

Berdasarkan uraian diatas maka kerangka konseptual yang dikembangkan dari penelitian ini dapat dilihat pada gambar 2 berikut :

Gambar 2

Kerangka Konseptual

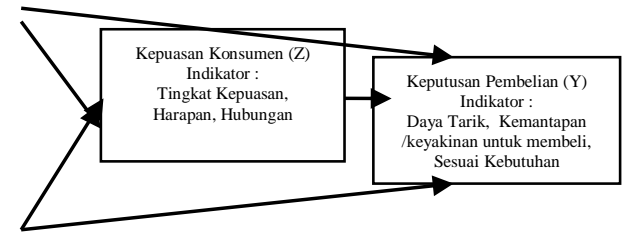

Sumber:data primer yang telah diolah 


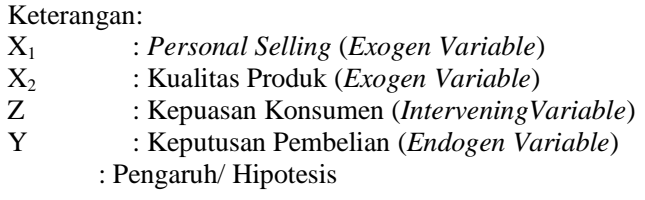

\section{METODE PENELITIAN}

Populasi dalam penelitian ini yaitu konsumen bagiak pelangi sari di Banyuwangi dengan sampel sebanyak 85 responden berdasarkan convenience sampling dimana proses pengambilan responden sebagai sampel berdasarkan kebetulanditemui cocok sebagai sumber data dengan kriteria utamanya adalah orang tersebut merupakan konsumen atau pembeli dari produk kue bagiak pelangi sari yang dipasarkan oleh Toko Kue Bagiak Pelangi Sari Banyuwangi.

Variabel dalam penelitian ini adalah personal selling $\left(\mathrm{X}_{1}\right)$ dengan indikator pendekatan, presentasi, mengatasi keberatan dan menutup penjualan.variabel kualitas produk dengan indikator kinerja, keistimewaan tambahan, kesesuaian dengan spesifikasi, tahan lama, perbaikan, keindahan, persepsi kualitas. Variabel kepuasan konsumen dengan indikator tingkat kepuasan, harapan, dan hubungan.variabel keputusan pembelian (Y) dengan indikator daya tarik, kemantapan/keyakinan untuk membeli,dan sesuai kebutuhan. Metode pengumpulan data yang digunakan adalah kuesioner dan wawancara.Teknik analisis data menggunakan analisis deskriptif persentase dan path analysis.

\section{HASIL DAN PEMBAHASAN}

\section{Uji Validitas Instrumen}

Nilai validitas pada dasarnya adalah nilai korelasi antara item dari masing-masing variabel dengan item total. Untuk menguji validitas dilakukan dengan teknik korelasi item total yang merupakan dasar dari korelasi pearson.

Adapun rumus korelasi pearson adalah:

$$
r_{x y}=\frac{N \Sigma X Y-(\Sigma X)(\Sigma Y)}{\sqrt{\left\{N \Sigma X^{2}-(\Sigma X)^{2}\right\}\left\{N \Sigma Y^{2}-(\Sigma Y)^{2}\right.}}
$$

Keterangan:

$\mathrm{r}=$ korelasi validitas item yang dicari

$\mathrm{x} \quad=$ skor yang diperoleh subyek dari seluruh item

$\mathrm{y}=$ skor total yang diperoleh subyek dari seluruh item

$\Sigma \mathrm{x} \quad=$ jumlah skor dalam distribusi $\mathrm{x}$

$\Sigma \mathrm{y} \quad=$ jumlah skor dalam distribusi $\mathrm{y}$

$\Sigma x^{2} \quad=$ jumlah kuadrat skor dalam distribusi $\mathrm{x}$

$\Sigma y^{2} \quad=$ jumlah kuadrat skor dalam distribusi $\mathrm{y}$

$\mathrm{N} \quad=$ jumlah responden
Pengujian validitas item menggunakan analisis korelasi bivariat dengan koefisien korelasi menggunakan pearson correlation dengan menggunakan software IBM SPSS versi 20. Dimana jika signifikansi yang diperoleh kurang dari 0.05 maka item tersebut dinyatakan valid pada taraf kepercayaan $95 \%$. Uji validitas dilakukan dengan membandingkan nilai rhitung dengan $r$ tabel.Jika $r$ hitung $>r$ tabel dan nilai positif maka butir pertanyaan tersebut dinyatakan valid (Ghozali, 2011:52).

\section{Uji Releabilitas Data}

Apabila koefisien releabilitas lebih dari 0,7 maka instrumen dinyatakan reliabel. Hasil lengkap uji reliabilitas instrumen terdapat pada tabel 2 tabel uji reliabilitas instrumen penelitian berikut.

Tabel 2

Uji reliabilitas instrumen penelitian

\begin{tabular}{|c|cc|c|}
\hline Variabel & $\begin{array}{c}\text { Cronbach's } \\
\text { Alpha }\end{array}$ & $\begin{array}{c}\text { Cronbach's } \\
\text { Alpha yang } \\
\text { disyaratkan }\end{array}$ & Kesimpulan \\
\hline $\begin{array}{c}\text { Personal } \\
\text { Selling }\end{array}$ & 0,787 & $>0,70$ & Reliabel \\
$\begin{array}{c}\text { Kualitas } \\
\text { Produk }\end{array}$ & 0,809 & $>0,70$ & Reliabel \\
$\begin{array}{c}\text { Kepuasan } \\
\text { Konsumen } \\
\text { Keputusan } \\
\text { Pembelian }\end{array}$ & 0,784 & $>0,70$ & Reliabel \\
\hline
\end{tabular}

Sumber:data primer yang telah diolah

Berdasarkan hasil pengujian dapat dijelaskan bahwa nilaiCronbach's Alpha lebih besar dari 0,70sehingga dapat disimpulkan bahwa semua instrument tersebut reliable.

\section{Analisis Deskriptif}

Tujuan penggunaan analisis deskriptif untuk mengetahui dominasi indikator yang menjadi alat ukut variabel penelitian. Adapun pengambilan keputusan didasarkan pada tabel 3 berikut:

Tabel 3

Kriteria Penafsiran Kondisi Variabel Penelitian

\begin{tabular}{cc}
\hline $\begin{array}{c}\text { Rata-Rata } \\
\text { Skor }\end{array}$ & Penafsiran \\
\hline$=4$ & Sangat Setuju \\
\hline$=3$ & Setuju \\
\hline$=2$ & Tidak Setuju \\
\hline$=1$ & Sangat Tidak Setuju \\
\hline Sumber: data primer yang telah diolah
\end{tabular}

Variabel personal selling $\left(\mathrm{X}_{1}\right)$ memiliki 4 indikator yaitu pendekatan, presentasi, mengatasi keberatan dan menutup penjualan. Data penelitian diperoleh berdasarkan hasil kuesioner yang ditanyakan langsung kepada responden.Berdasarkan hasil penelitian diperoleh data rata-rata tentang variabel personal selling seperti tabel 9berikut. 
Tabel 4

analisis deskriptif variabel personal selling

\begin{tabular}{cccc}
\hline $\begin{array}{c}\text { Variable } \\
\text { Personal } \\
\text { Selling }\end{array}$ & $\begin{array}{c}\text { Rata- } \\
\text { rata }\end{array}$ & Prosentase & Ket. \\
\hline Pendekatan & 2,66 & $28 \%$ & $\begin{array}{c}\text { Cukup } \\
\text { Baik }\end{array}$ \\
\hline Presentasi & 2,54 & $27 \%$ & $\begin{array}{c}\text { Cukup } \\
\text { Baik }\end{array}$ \\
\hline $\begin{array}{c}\text { Mengatasi } \\
\text { Keberatan }\end{array}$ & 2,33 & $24 \%$ & $\begin{array}{c}\text { Cukup } \\
\text { Baik }\end{array}$ \\
\hline $\begin{array}{c}\text { Menutup } \\
\text { Penjualan }\end{array}$ & 2,02 & $21 \%$ & $\begin{array}{c}\text { Kurang } \\
\text { Baik }\end{array}$ \\
\hline
\end{tabular}

Berdasarkan tabel 4 diatas, rata-rata paling tinggi secara berurutan terdapat pada indikator pendekatandengan keterangan cukup baik sebesar 2,66 (28\%), presentasidengan keterangan cukup baik sebesar 2,54 (27\%) dan mengatasi keberatandengan keterangan cukup baik sebesar 2,30 (24\%). Sementara indikatorvariabel personal selling selanjutnya yaitu menutup penjualan dengan keterangan kurang baik sebesar 2,02 $(21 \%)$.

Sedangkan variabel Kualitas $\operatorname{Produk}\left(\mathrm{X}_{2}\right)$ memiliki indikator yaitu kinerja, keistimewaan tambahan, kesesuaian dengan spesifikasi, daya tahan, perbaikan, keindahan dan kualitas yang dipersepsikan.

Data penelitian diperoleh berdasarkan hasil kuesioner yang ditanyakan langsung kepada responden.Berdasarkan hasil penelitian diperoleh data rata-rata tentang variabel personal selling seperti tabel 5 berikut.

Tabel 5

analisis deskriptif variabel Kualitas Produk

\begin{tabular}{cccc}
\hline $\begin{array}{c}\text { Variable } \\
\text { Kualitas } \\
\text { Produk }\end{array}$ & $\begin{array}{c}\text { Rata- } \\
\text { rata }\end{array}$ & Prosentase & Keterangan \\
\hline Kinerja & 2,42 & $15 \%$ & Cukup Baik \\
\hline $\begin{array}{c}\text { Keistimewaan } \\
\text { tambahan }\end{array}$ & 2,21 & $14 \%$ & Cukup Baik \\
\hline $\begin{array}{c}\text { Kesesuian } \\
\text { dengan } \\
\text { spesifikasi }\end{array}$ & 2,31 & $15 \%$ & Cukup Baik \\
\hline Daya tahan & 2,22 & $14 \%$ & Cukup Baik \\
\hline $\begin{array}{c}\text { Perbaikan } \\
\text { Keindahan }\end{array}$ & 2,16 & $13 \%$ & $\begin{array}{c}\text { Kurang } \\
\text { Baik }\end{array}$ \\
\hline $\begin{array}{c}\text { Kaitas yang } \\
\text { dipersepsikan }\end{array}$ & 2,38 & $15 \%$ & $\begin{array}{c}\text { Kurang } \\
\text { Baik }\end{array}$ \\
\hline Sumber:data primer yang telah diolah &
\end{tabular}

Berdasarkan tabel 5 diatas, rata-rata paling tinggi secara berurutan terdapat pada indikator kinerja dengan keterangan cukup baik sebesar 2,42 (15\%), kesesuian dengan spesifikasi dengan keterangan cukup baik sebesar 2,31 (15\%) dan kualitas yang dipersepsikan dengan keterangan cukup baik sebesar 2,38 (15\%), sedangkan daya tahan dengan keterangan cukup baik sebesar 2,22 (14\%) dan keindahan dengan keterangan kurang baik sebesar 2,16 (14\%). Sementara indikatorvariabel personal selling selanjutnya perbaikan dengan keterangan kurang baik yaitu sebesar 2,00 (13\%).

Untuk variabel Kepuasan konsumen (Z) memiliki indikator yaitu tingkat kepuasan, harapan dan hubungan. Data penelitian diperoleh berdasarkan hasil kuesioner yang ditanyakan langsung kepada responden.Berdasarkan hasil penelitian diperoleh data rata-rata tentang variabel personal selling seperti tabel 6 berikut.

Tabel 6

analisis deskriptif variabel Kepuasan Konsumen

\begin{tabular}{cccc}
\hline $\begin{array}{c}\text { Variable } \\
\text { Kepuasan } \\
\text { Konsumen }\end{array}$ & $\begin{array}{c}\text { Rata- } \\
\text { rata }\end{array}$ & Prosentase & Keterangan \\
\hline $\begin{array}{c}\text { Tingkatan } \\
\text { kepuasan }\end{array}$ & 2,73 & $37 \%$ & Cukup Baik \\
\hline Harapan & 2,45 & $34 \%$ & Cukup Baik \\
\hline Hubungan & 2,11 & $29 \%$ & $\begin{array}{c}\text { Kurang } \\
\text { Baik }\end{array}$ \\
\hline
\end{tabular}

Sumber:data primer yang telah diolah

Berdasarkan tabel 6 diatas, rata-rata paling tinggi secara berurutan terdapat pada indikator tingkatan kepuasan dengan keterangan cukup baik sebesar 2,73 (37\%), harapan dengan keterangan cukup baik sebesar 2,45 (34\%) dan kualitas yang dipersepsikan dengan keterangan kurang baik sebesar 2,11 (29\%),

Dan yang terakhir variabel Keputusan Pembelian (Y) memiliki indikator yaitu tingkat kepuasan, harapan dan hubungan. Data penelitian diperoleh berdasarkan hasil kuesioner yang ditanyakan langsung kepada responden.Berdasarkan hasil penelitian diperoleh data rata-rata tentang variabel personal selling seperti tabel 7 berikut.

Tabel 7

analisis deskriptif variabel Keputusan Pembelian

\begin{tabular}{cccc}
\hline $\begin{array}{c}\text { Variable } \\
\text { Keputusan } \\
\text { Pembelian }\end{array}$ & $\begin{array}{c}\text { Rata- } \\
\text { rata }\end{array}$ & Prosentase & Ket. \\
\hline Daya tarik & 2,19 & $30 \%$ & $\begin{array}{c}\text { Kurang } \\
\text { Baik }\end{array}$ \\
\hline Kemantapan & 2,66 & $37 \%$ & Cukup Baik \\
\hline $\begin{array}{c}\text { Sesuai } \\
\text { kebutuhan }\end{array}$ & 2,35 & $33 \%$ & Cukup Baik \\
\hline Sumber:data primer yang telah diolah &
\end{tabular}

Berdasarkan tabel 7 diatas, rata-rata paling tinggi secara berurutan terdapat pada indikator kemantapan dengan keterangan cukup baik sebesar 2,66 (37\%) dan sesuai kebutuhan dengan keterangan cukup baik sebesar 2,35 (33\%), daya tarik dengan keterangan kurang baik sebesar 2,19 (30\%). 


\section{Analysis Inferensial}

Analisis sub struktural A

Analisis substruktural 1 merupakan analisis path dengan variabel exogenpersonal selling, kualitas produk serta pengaruhnya terhadap kepuasan konsumen sebagai variabel intervening. Analisis yang digunakan adalah regresi berganda. Analisis regresi berganda ini digunakan untuk menjawab permasalahan 1 hingga 3 . Hasil analisis substruktural 1 seperti terdapat pada tabel 8 tabel 9 dan tabel 10 berikut.

Tabel 8

Tabel model 1summary substruktural A

\begin{tabular}{|c|c|c|c|c|}
\hline Model & $\mathrm{R}$ & $\begin{array}{c}\mathrm{R} \\
\text { Square }\end{array}$ & $\begin{array}{c}\text { Adjusted R } \\
\text { Square }\end{array}$ & $\begin{array}{c}\text { Std. Error of } \\
\text { the Estimate }\end{array}$ \\
\hline 1 &, $850^{\mathrm{a}}$ & 0,722 & 0,716 & 1,3098 \\
\hline
\end{tabular}

Predictors: (Constant), Kualitas Produk, Personal Selling

Dependent Variable: Kepuasan Konsumen Tabel 9

Tabel koefisien model 1 substruktural A

\begin{tabular}{|c|c|c|c|c|c|c|}
\hline \multirow[t]{2}{*}{ Model } & & \multicolumn{2}{|c|}{$\begin{array}{c}\text { Unstandar } \\
\text { dized } \\
\text { Coefficient } \\
\text { s }\end{array}$} & $\begin{array}{c}\text { Stand } \\
\text { ardize } \\
d \\
\text { Coeff }\end{array}$ & \multirow[t]{2}{*}{$\mathrm{T}$} & \multirow[t]{2}{*}{ Sig. } \\
\hline & & B & $\begin{array}{l}\text { Std } \\
\text { Err } \\
\text { or }\end{array}$ & Beta & & \\
\hline \multirow{3}{*}{1} & (Constant) & $\begin{array}{l}1,3 \\
9\end{array}$ & $\begin{array}{l}1,8 \\
45\end{array}$ & \multirow{3}{*}{0,465} & 0,754 & $\begin{array}{l}0,4 \\
53\end{array}$ \\
\hline & $\begin{array}{l}\text { Personal } \\
\text { Selling }\end{array}$ & $\begin{array}{l}0,3 \\
6\end{array}$ & $\begin{array}{l}0,0 \\
7\end{array}$ & & 5,16 & 0 \\
\hline & $\begin{array}{l}\text { Kualitas } \\
\text { Produk }\end{array}$ & $\begin{array}{l}0,2 \\
14\end{array}$ & $\begin{array}{l}0,0 \\
44\end{array}$ & & 4,885 & 0 \\
\hline
\end{tabular}

Dependent Variable: Kepuasan Konsumen Tabel 10

Tabel anova model 1 substruktural A

\begin{tabular}{|c|c|c|c|c|c|c|}
\hline Model & $\begin{array}{c}\text { Sum of } \\
\text { Squares }\end{array}$ & Df & $\begin{array}{c}\text { Mean } \\
\text { Square }\end{array}$ & \multicolumn{1}{|c|}{ F } & Sig. \\
\hline & $\begin{array}{l}\text { Regre } \\
\text { ssion }\end{array}$ & 366,085 & 2 & 183,04 & 106,70 &, $000^{\mathrm{b}}$ \\
$\begin{array}{l}\text { 1 } \\
1\end{array}$ & $\begin{array}{l}\text { Resid } \\
\text { ual }\end{array}$ & 140,668 & 82 & 1,715 & & \\
& Total & 506,753 & 84 & & & \\
\hline
\end{tabular}

a. Dependent Variable: Kepuasan Konsumen

b. Predictors: (Constant), Kualitas Produk, Personal Selling

a. Analisis Koefisien Determinasi ( $\left.\mathrm{R}^{2}\right)$

Berdasarkan tabel 8 Tabel model 1 summary sub-struktural 1 diperoleh nilai koefisien determinasi totalnya (Adjusted $\mathrm{R}^{2}$ ) sebesar 0,716 dengan demikian maka besarnya konstribusi untuk personal selling, kualitas produk secara bersamasama terhadap variabel kepuasan konsumen di Toko Kue Bagiak Pelangi Sari Banyuwangi adalah sebesar $71,6 \%$. Sementara sisanya sebesar $28,4 \%$ dipengaruhi oleh variabel lain selain personal selling, kualitas produk yang tidak diikutkan dalam penelitian ini. b. Uji T (Uji Parsial)

Untuk mengetahui apakah masing-masing variabel bebasnya secara sendiri-sendiri berpengaruh secara signifikan terhadap variable terikatnya maka dapat dilakukan dengan memperhatikan tabel 9 Tabel koefisien model 1 substruktural A. Hasil pada tabel 9 diperoleh dengan menggunakan software IBM SPSS versi 20. Kriteria pengambilan keputusan adalah bilamana $\mathrm{T}_{\text {tabel }}>\mathrm{T}_{\text {hitung, }} \mathrm{H}_{0}$ diterima atau jika $\mathrm{T}_{\text {tabel }}<$ $\mathrm{T}_{\text {hitung, maka }} \mathrm{H}_{\mathrm{a}}$ diterima, begitupun jika sig $>\alpha$ (0.05), maka $\mathrm{H}_{0}$ diterima $\mathrm{H}_{1}$ ditolak dan jika sig $<\alpha$ $(0,05)$, maka maka $\mathrm{H}_{0}$ ditolak $\mathrm{H}_{\mathrm{a}}$ diterima.Hipotesis pengujian adalah sebagai berikut:

$\mathrm{H}_{0}: \rho=0$ Tidak ada pengaruh variabel bebas/antara terhadap variabel antara/terikat di toko kue bagiak pelangi Sari Banyuwangi.

$\mathrm{H}_{1}: \rho \mathrm{x}_{1} \mathrm{Z} \neq 0$ Personal Selling berpengaruh terhadap Kepuasan Konsumen di toko kue bagiak pelangi sari Banyuwangi.

$\mathrm{H}_{2}: \rho \mathrm{x}_{2} \mathrm{Z} \neq 0$ Kualitas Produk berpengaruh terhadap Kepuasan Konsumen di toko bagiak pelangi sari Banyuwangi.

Dengan hipotesis signifikansi sebagai berikut :

$\mathrm{H}_{0}$ :angkasignifikan $(\mathrm{Sig})>0,05$ maka variabel bebas berpengaruh secara tidak signifikan terhadap variabel terikatnya.

$\mathrm{H}_{1}$ :angka signifikan $(\mathrm{Sig})<0,05$ maka variabel bebas berpengaruh secara signifikan terhadap variabel terikatnya.

Berdasarkan tabel 9 di atas, diperoleh nilai $\rho \mathrm{X}_{1} \mathrm{Z}=0,465$ dengan sig 0,000 , maka dapat dinyatakan bahwa $\mathrm{H}_{0}$ ditolak karena $\rho \mathrm{X}_{1} \mathrm{Z} \neq 0$ sekaligus $\mathrm{H}_{11}$ diterima. Artinya personal selling berpengaruh terhadap kepuasan konsumen Toko Kue Bagiak Pelangi Sari Banyuwangi. Dengan memperhatikan hasil signifikansi $0,000<0,05$ maka dapat dinyatakan bahwa personal selling di Toko Kue Bagiak Pelangi Sari Banyuwangi berpengaruh secara signifikan terhadap kepuasan konsumen di Toko Kue Bagiak Pelangi Sari Banyuwangi.

Berdasarkan tabel 9 di atas, diperoleh nilai $\rho \mathrm{X}_{2} \mathrm{Z}=0,440$ dengan sig 0,000 , maka dapat dinyatakan bahwa $\mathrm{H}_{0}$ ditolak karena $\rho \mathrm{X}_{2} \mathrm{Z} \neq 0$ sekaligus $\mathrm{H}_{12}$ diterima. Artinya kualitas produk berpengaruh terhadap kepuasan konsumen Toko Kue Bagiak Pelangi Sari Banyuwangi. Dengan memperhatikan hasil signifikansi $0,000<0,05$ maka dapat dinyatakan bahwa kualitas produk di Toko Kue Bagiak Pelangi Sari Banyuwangi berpengaruh secara signifikan terhadap kepuasan konsumen di Toko Bagiak Pelangi Sari Banyuwangi.

c. Uji F

Secara keseluruhan untuk melihat pengaruh variabel bebas secara bersama-sama terhadap 
variable terikat maka dapat dilakukan dengan memperhatikan tabel Tabel 10 tabel anova model 1 substruktural A. Pengujian ini dilakukan untuk mengetahui apakah secara simultan, koefisien regresi variable bebas mempunyai pengaruh nyata atau tidak terhadap variable terikat. Kriteria pengambilan keputusan adalah dengan memperhatikan nilai $F_{\text {hitung }}$ dikonstantakan dengan $\mathrm{F}_{\text {tabel, }}$ dengan menggunakan tingkat keyakinan $95 \%$ dengan taraf kesalahan $(\alpha)$ yang digunakan yaitu $5 \%$ atau 0,05 maka, $F_{\text {hitung }}>$ dari $\mathrm{F}_{\text {tabel }}$ atau sig $<(\alpha)$ 0,05 berarti variabel bebasnya secara bersamasama memberikan pengaruh yang signifikan terhadap variabel terikat. Hipotesis pengujian uji anova adalah sebagai berikut:

$\mathrm{H}_{0}$ :angkasignifikan (Sig) > 0,05 maka variabel bebas secara bersama-sama tidak berpengaruh terhadap variabel terikatnya.

$\mathrm{H}_{1}$ :angka signifikan $(\mathrm{Sig})<0,05$ maka variabel bebas secara bersama-sama berpengaruh terhadap variabel terikatnya.

Berdasarkan tabel 10 tabel anova model 1 substrukturalA diperoleh nilai $F_{\text {hitung }}$ sebesar 106,702 dengan nilai sig $=0,000$. Berdasarkan perhitungan software IBM SPSS versi 20 diperoleh nilai $F_{\text {hitung }}$ sebesar 106,702, dengan mengambil taraf signifikan asebesar 5\%, maka dari tabel distribusi $\mathrm{F}$ di dapat nilai $\mathrm{F}_{\text {tabeluntuk } \mathrm{n}=}$ $85 ; \mathrm{k}=2 ; \mathrm{df}=\mathrm{n}-\mathrm{k}-1=85-2-1=83$; diperoleh nilai $\mathrm{F}_{\text {table }}$ sebesar 19,484 .

Dikarenakan $\quad F_{\text {hitung }}>\quad F_{\text {tabel }} \quad$ yaitu 106,702>19,484, dan karena Karena sig< 0,05 maka $\mathrm{H}_{0}$ ditolak sekaligus $\mathrm{H}_{1}$ diterima. Sehingga dapat dinyatakan bahwa variabel personal selling, kualitas produk secara bersama-sama berpengaruh terhadap kepuasan konsumen toko bagiak pelangi sari Banyuwangi.

\section{Analisis sub struktural B}

Analisis substruktural B merupakan analisis path dengan variabel endogen personal selling, kualitas produk dan kepuasan konsumen serta pengaruhnya terhadap keputusan pembelian sebagai variabel exogen. Analisis yang digunakan adalah regresi berganda. Analisis regresi berganda ini digunakan untuk menjawab permasalah 4 hingga 6. Hasil analisis substruktural 2 seperti terdapat pada tabel 11, tabel 12 dan tabel 13 berikut.

Tabel 11

Tabel model 2 summary substruktural 2

\begin{tabular}{|r|c|r|r|r|}
\hline Model & $\mathrm{R}$ & $\begin{array}{c}\mathrm{R} \\
\text { Square }\end{array}$ & $\begin{array}{c}\text { Adjusted } \\
\text { R Square }\end{array}$ & $\begin{array}{c}\text { Std. Error } \\
\text { of the } \\
\text { Estimate }\end{array}$ \\
\hline 1 &, $854^{\mathrm{a}}$ & 0,729 & 0,719 & 1,4637 \\
\hline
\end{tabular}

a. Predictors: (Constant), Kepuasan Konsumen, Kualitas Produk, Personal Selling b. Dependent Variable: Keputusan Pembelian

Tabel 12

Tabel koefisien model 2 substruktural 2

\begin{tabular}{|c|c|c|c|c|c|c|}
\hline \multirow{2}{*}{\multicolumn{2}{|c|}{ Model }} & \multicolumn{2}{|c|}{$\begin{array}{c}\text { Unstandardized } \\
\text { Coefficients }\end{array}$} & \multirow{2}{*}{$\begin{array}{c}\text { Standa } \\
\text { rdized } \\
\text { Coeffi } \\
\text { cients }\end{array}$} & \multirow[t]{2}{*}{$\mathrm{t}$} & \multirow[t]{2}{*}{ Sig. } \\
\hline & & B & $\begin{array}{l}\text { Std. } \\
\text { Error }\end{array}$ & & & \\
\hline & (Constant) & $\begin{array}{l}- \\
1,68 \\
5\end{array}$ & 2,069 & & $\begin{array}{l}- \\
0,81 \\
4\end{array}$ & $\begin{array}{l}0,41 \\
8\end{array}$ \\
\hline & $\begin{array}{l}\text { Personal } \\
\text { Selling }\end{array}$ & $\begin{array}{l}0,26 \\
8\end{array}$ & 0,09 & 0,308 & $\begin{array}{l}2,98 \\
8\end{array}$ & $\begin{array}{l}0,00 \\
4\end{array}$ \\
\hline & $\begin{array}{l}\text { Kualitas } \\
\text { Produk }\end{array}$ & $\begin{array}{l}0,16 \\
3\end{array}$ & 0,056 & 0,298 & $\begin{array}{l}2,93 \\
1\end{array}$ & $\begin{array}{l}0,00 \\
4\end{array}$ \\
\hline 1 & $\begin{array}{l}\text { Kepuasan } \\
\text { Konsumen }\end{array}$ & $\begin{array}{l}0,35 \\
5\end{array}$ & 0,123 & 0,316 & $\begin{array}{l}2,87 \\
8\end{array}$ & $\begin{array}{l}0,00 \\
5\end{array}$ \\
\hline
\end{tabular}

Tabel 13

Tabel anova model 2 substruktural 2

\begin{tabular}{|c|c|c|c|c|c|c|}
\hline \multicolumn{2}{|c|}{ Model } & $\begin{array}{l}\text { Sum of } \\
\text { Squares }\end{array}$ & $\overline{\mathrm{Df}}$ & $\begin{array}{c}\text { Mean } \\
\text { Square }\end{array}$ & $\bar{F}$ & Sig. \\
\hline \multirow{3}{*}{1} & Regression & 467,367 & 3 & 155,789 & 72,72 &, $000^{\mathrm{b}}$ \\
\hline & Residual & 173,527 & 81 & 2,142 & & \\
\hline & Total & 640,894 & 84 & & & \\
\hline
\end{tabular}

Dependent Variable: Keputusan Pembelian

Predictors: (Constant), Kepuasan Konsumen,

Kualitas Produk,Personal Selling

a. Analisis Koefisien Determinasi ( $\left.\mathrm{R}^{2}\right)$

Berdasarkan tabel 11 Tabel model 2summary substruktural B diperoleh nilai koefisien determinasi totalnya (Adjusted $\mathrm{R}^{2}$ ) sebesar 0, 719 dengan demikian maka besarnya konstribusi untuk personal selling, kualitas produk dan kepuasan konsumen secara bersama-sama terhadap variabel keputusan pembelian di toko bagiak pelangi sari Banyuwangi adalah sebesar $71,9 \%$. Sementara sisanya sebesar $28,1 \%$ dipengaruhi oleh variabel lain selain personal selling, kualitas produk dan kepuasan konsumen yang tidak diikutkan dalam penelitian ini.

b. Uji T (Uji Parsial)

Untuk mengetahui apakah masing-masing variabel bebasnya secara sendiri-sendiri berpengaruh secara signifikan terhadap variable terikatnya maka dapat dilakukan dengan memperhatikan tabel 12 Tabel koefisien model 2 substruktural B. Hasil pada tabel 12 diperoleh dengan menggunakan software IBM SPSS versi 20. Kriteria pengambilan keputusan adalah bilamana $\mathrm{T}_{\text {tabel }}>\mathrm{T}_{\text {hitung, }} \mathrm{H}_{0}$ diterima atau jika $\mathrm{T}_{\text {tabel }}<$

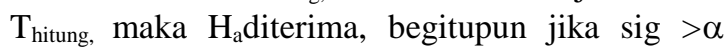
(0.05), maka $\mathrm{H}_{0}$ diterima $\mathrm{H}_{1}$ ditolak dan jika sig $<\alpha$ $(0,05)$, maka maka $\mathrm{H}_{0}$ ditolak $\mathrm{H}_{\mathrm{a}}$ diterima.Hipotesis pengujian adalah sebagai berikut: 
$\mathrm{H}_{0}: \rho=0$ Tidak ada pengaruh variabel bebas/antara terhadap variabel antara/terikat di toko bagiak pelangi sariBanyuwangi.

$\mathrm{H}_{3}: \rho_{\mathrm{x} 1 \mathrm{z}} \neq 0$ Personal Selling berpengaruh terhadap Keputusan Pembelian di toko bagiak pelangi sari Banyuwangi.

$\mathrm{H}_{4}: \rho_{\mathrm{x} 2 \mathrm{z}} \neq 0$ Kualitas Produk berpengaruh terhadap Keputusan Pembelian di toko bagiak pelangi sari Banyuwangi.

$\mathrm{H}_{5}: \rho_{\mathrm{x} 3 \mathrm{z}} \neq 0$ Kepuasan Konsumen berpengaruh terhadap Keputusan Pembelian di toko bagiak pelangi sari Banyuwangi.

Dengan hipotesis signifikansi sebagai berikut :

$\mathrm{H}_{0}$ :angkasignifikan (Sig) > 0,05 maka variabel endogen berpengaruh secara tidak signifikan terhadap variabel exogen.

$\mathrm{H}_{1}$ :angka signifikan (Sig) $<0,05$ maka variabel endogen berpengaruh secara signifikan terhadap variabel exogen.

Berdasarkan tabel 12 di atas, diperoleh nilai $\rho_{\mathrm{X} 1 . \mathrm{Y}}=0,308$ dengan sig 0,004 , maka dapat dinyatakan bahwa $\mathrm{H}_{0}$ ditolak karena $\rho_{\mathrm{X} 1 . \mathrm{Y}} \neq 0$ sekaligus $\mathrm{H}_{1}$ diterima. Artinya personal selling berpengaruh signifikan dengan keputusan pembelian. Dengan memperhatikan hasil signifikansi $0,004<0,05$ maka dapat dinyatakan bahwa personal selling di toko bagiak pelangi sari Banyuwangi berpengaruh secara signifikan terhadap keputusan pembelian di toko bagiak pelangi sari Banyuwangi.

Berdasarkan tabel 12 di atas, diperoleh nilai $\rho_{\mathrm{X} 2 \mathrm{Y}}=0,298$ dengan sig 0,004, maka dapat dinyatakan bahwa $\mathrm{H}_{0}$ ditolak karena $\rho_{\mathrm{X} 2 . \mathrm{Y}} \neq 0$ sekaligus $\mathrm{H}_{2}$ diterima. Artinya kualitas produk berpengaruh terhadap keputusan pembelian Toko Bagiak Pelangi Sari Banyuwangi. Dengan memperhatikan hasil signifikansi $0,004<0,05$ maka dapat dinyatakan bahwa kualitas produk di toko bagiak pelangi sari Banyuwangi berpengaruh secara signifikan terhadap keputusan pembelian di toko bagiak. pelangi sari Banyuwangi.

Berdasarkan tabel 12 di atas, diperoleh nilai $\rho_{\mathrm{Z} . \mathrm{Y}}=0,316$ dengan sig 0,005 , maka dapat dinyatakan bahwa $\mathrm{H}_{0}$ ditolak karena $\rho_{\text {Z.Y }} \neq 0$ sekaligus $\mathrm{H}_{3}$ diterima. Artinya Kepuasan Konsumen berpengaruh terhadap keputusan pembelian Toko Bagiak Pelangi Sari Banyuwangi. Dengan memperhatikan hasil signifikansi $0,005<$ 0,05 maka dapat dinyatakan bahwa motivasi kerja karyawan di toko bagiak pelangi sari Banyuwangi berpengaruh secara signifikan terhadap keputusan pembelian di toko bagiak pelangi sari Banyuwangi.

c. $\mathrm{Uji} F$

Secara keseluruhan untuk melihat pengaruh variable bebas secara bersama-sama terhadap variable terikat maka dapat dilakukan dengan memperhatikan tabel Tabel 13 tabel anova model 2 substruktural 2.

Pengujian ini dilakukan untuk mengetahui apakah secara simultan, koefisien regresi variable bebas mempunyai pengaruh nyata atau tidak terhadap variable terikat. Kriteria pengambilan keputusan adalah dengan memperhatikan nilai


menggunakan tingkat keyakinan $95 \%$ dengan taraf kesalahan $(\alpha)$ yang digunakan yaitu $5 \%$ atau 0,05 maka, $F_{\text {hitung }}>$ dari $F_{\text {tabel }}$ atau sig $<(\alpha) 0,05$ berarti variabel bebasnya secara bersama-sama memberikan pengaruh yang signifikan terhadap variabel terikat. Hipotesis pengujian uji anova adalah sebagai berikut:

$\mathrm{H}_{0}: \mathrm{F}_{\text {hitung }}<\mathrm{F}_{\text {tabel }}$ maka variabel endogen secara bersama-sama tidak berpengaruh terhadap variabel exogen.

$\mathrm{H}_{1}: \mathrm{F}_{\text {hitung }}>\mathrm{F}_{\text {tabel }}$ maka variabel endogen secara bersama-sama tidak berpengaruh terhadap variabel exogen.

Berdasarkan tabel 13 tabel anova model 2 substruktural $B$ diperoleh nilai $F_{\text {hitung }}$ sebesar 72,720 dengan nilai sig $=0,000$. Berdasarkan perhitungan software IBM SPSS versi 20 diperoleh nilai $F_{\text {hitungsebesar 98,434, dengan }}$ mengambil taraf signifikan asebesar 5\%, maka dari tabel distribusi Fdidapat nilai $\mathrm{F}_{\text {tabel }}$ untuk $\mathrm{n}=$ $85 ; \mathrm{k}=4 ; \mathrm{df}=\mathrm{n}-\mathrm{k}-1=85-4-1=80 ;$ diperoleh nilai $F_{\text {tabel }}$ sebesar 8,560. Dikarenakan $F_{\text {hitung }}>F_{\text {tabel }}$ yaitu $72,720>8,560$, dan karena $s i g<0,05$ maka $\mathrm{H}_{0}$ ditolak sekaligus $\mathrm{H}_{1}$ diterima. Sehingga dapat dinyatakan bahwa variabel personal selling, kualitas produk dan kepuasan konsumen secara bersama-sama berpengaruh terhadap keputusan pembelian di toko bagiak pelangi sari Banyuwangi.

\section{Analisis Path}

Berdasarkan hasil pada analisis substruktural 1 dan substruktural 2 maka hasil analisis path untuk seluruh variabel dapat diketahui baik pengaruh langsung maupun pengaruh tidak langsung sebagai berikut:

A. Penghitungan pengaruh langsung (Direct Effect atau DE)

1. Pengaruh langsung personal selling terhadap keputusan pembelian. $\mathrm{X}_{1} \rightarrow \mathrm{Y}=0,308$.

2. Pengaruh langsung kualitas produk terhadap keputusan pembelian. $\mathrm{X}_{2} \rightarrow \mathrm{Y}=0,298$.

3. Pengaruh langsung personal selling terhadap keputusan pembelian. $\mathrm{X}_{1} \rightarrow \mathrm{Z}=0,465$.

4. Pengaruh langsung kualitas produk terhadap keputusan pembelian. $\mathrm{X}_{2} \rightarrow \mathrm{Z}=0,440$. 
5. Pengaruh langsung kepuasan konsumen terhadap keputusan pembelian. $\mathrm{Z} \rightarrow \mathrm{Y}=0,316$.

B. Penghitungan pengaruh tidak langsung (Indirect Effect atau IE)

1. Pengaruh tidak langsung personal selling terhadap keputusan pembelian. $\mathrm{X}_{1} \rightarrow \mathrm{Z} \rightarrow \mathrm{Y}=0,465 \times 0,316=0,147$.

2. Pengaruh tidak langsung kualitas produk terhadap keputusan pembelian. $\mathrm{X}_{2} \rightarrow \mathrm{Z} \rightarrow \mathrm{Y}=0,440 \times 0,298=0,139$.

Untuk menghitung koefisien residu $\rho_{\mathrm{y}} \varepsilon_{1}=$ $\sqrt{1-0,716}=0,533$ dan koefisien residu $\rho_{\mathrm{z}} \varepsilon_{2}=$ $\sqrt{1-0,719}=0,530$

Gambar 3

Pengaruh langsung $(D E)$ dan tidak langsung $(I E)$ variabel Personal Selling

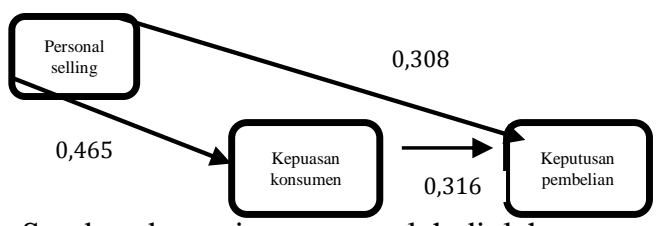

Sumber:data primer yang telah diolah

Gambar 3 Pengaruh langsung $(D E)$ dan tidak langsung (IE) variabel kepemimpinan menunjukkan bahwa pengaruh langsung variabel personal selling terhadap keputusan pembelian adalah sebesar 0,308.Pengaruh langsung variabel personal selling terhadap kepuasan konsumen adalah sebesar 0,465 dan pengaruh langsung variabel kepuasan konsumen terhadap keputusan pembelian adalah sebesar 0,316.Dengan demikian maka pengaruh tidak langsung variabel personal selling terhadap keputusan pembelian adalah sebesar $0,147(0,465 \times 0,316=0,147)$.

Gambar 4

Pengaruh langsung $(D E)$ dan tidak langsung $(I E)$ variabel Kualitas Produk

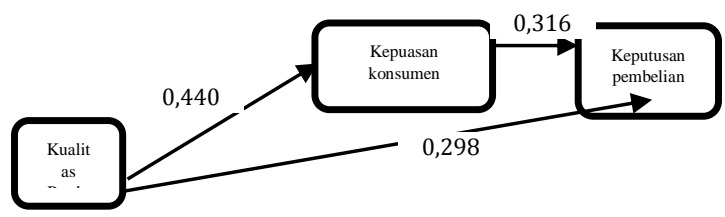

Sumber:data primer yang telah diolah

Gambar 4 Pengaruh langsung $(D E)$ dan tidak langsung (IE) variabel kepemimpinan menunjukkan bahwa pengaruh langsung variabel kualitas produk terhadap keputusan pembelian adalah sebesar 0,298.Pengaruh langsung variabel kualitas produk terhadap kepuasan konsumen adalah sebesar 0,440 dan pengaruh langsung variabel kepuasan konsumen terhadap keputusan pembelian adalah sebesar 0,316.Dengan demikian maka pengaruh tidak langsung variabel kualitas produk terhadap keputusan pembelian adalah sebesar $0,131(0,440 \times 0,316=0,131)$.

\section{Pembahasan}

\section{Pengaruh Personal Selling terhadap Kepuasan} Konsumen

Pembuktian hipotesis pertama Personal Selling atau penjualan pribadi berkaitan dengan kemampuan karyawan atau manajemen perusahaan dalam memberikan pelayanan secara individu untuk menciptakan penjualan bagi perusahaan, melalui kepuasan dari para konsumennya. Artinya kepuasan konsumen dipengaruhi oleh personal selling sehingga variabel personal selling didominasi oleh indikator pendekatan dengan tingkatan kepuasan konsumen yang cukup baik, Masterson dan Pickton (2004:256) menyatakan personal selling adalah presentasi secara lisan, dan percakapan dengan satu pembeli yang potensial, dengan tujuan mendapatkan penjualan.

Hasil penelitian tersebut, sejalan dengan penelitian Darmo (2013) judul penelitian pengaruh personal selling \& sales promotion terhadap kepuasan konsumen (studi kasus : jne duta square), dan penelitian Satriyo U.P. Bhaskara (2012), yang menemukan bahwa CRM, Personal Selling Berpengaruh Signifikan Terhadap kepuasan konsumen.Dengan demikian hasil uji penelitian yang dilakukan terbukti.

\section{Pengaruh Kualitas Produk terhadap Kepuasan Konsumen}

Pembuktian hipotesis kedua kualitas produk terhadap kepuasan konsumen berpengaruh signifikan terbukti hasil penelitian tersebut, Artinya kepuasan konsumen dipengaruhi oleh kualitas produk yang dihasilkan terbukti dari observasi yang dilakukan peneliti variabel kualitas produk didominasi oleh kinerja karyawan toko kue bagiak dengan tingkatan kepuasan konsumen yang cukup baik,

JURNAL MANAJEMEN PEMASARAN Vol. 1, No. 2, (2013) 1-8 DennyIrawan (2013) "Analisa pengaruh kualitas produk terhadap loyalitas melalui kepuasan sebagai variabel intervening pada konsumen restoran por kee Surabaya" penelitian ini juga sejalan dengan penelitian Mulyono (2008), yang menganalisis pengaruh kualitas produk terhadap kepuasan konsumen adalah positip dan signifikan dan Pusparani (2012) dengan judul Pengaruh kualitas produk dan brand image terhadap kepuasan konsumen dan loyalitas konsumen kamera canon digital single lens reflex (dslr) di kota Denpasar. Dengan demikian hasil uji penelitian yang dilakukan terbukti. 


\section{Kesimpulan}

1 Hipotesis pertama yang secara teoretik menduga bahwa personal selling berpengaruh terhadap kepuasan konsumensecara empirik terbukti signifikan, sehingga $\mathrm{H}_{1}$ diterima. Jadi semakin baik kemampuan personal selling akan berpengaruh terhadap kepuasan konsumen di toko bagiak pelangi sari Banyuwangi.

2 Hipotesis kedua yang secara teoretik menduga bahwa kualitas produk berpengaruh terhadap kepuasan konsumensecara empirik terbukti signifikan, sehingga $\mathrm{H}_{2}$ diterima. Jadi semakin baik kualitas produk akan berpengaruh terhadap kepuasan konsumen di toko bagiak pelangi sari Banyuwangi.

3 Hipotesis ketiga yang secara teoretik menduga bahwa personal selling berpengaruh terhadap keputusan pembelian secara empirik terbukti signifikan, sehingga $\mathrm{H}_{3}$ diterima. Jadi semakin baik kemampuanpersonal selling akan berpengaruh terhadap keputusan pembelian di toko bagiak pelangi sari Banyuwangi.

4 Hipotesis keempat yang secara teoretik menduga bahwa kualitas produk berpengaruh terhadap keputusan pembeliansecara empirik terbukti signifikan, sehingga $\mathrm{H}_{4}$ diterima. Jadi semakin baik kualitas produk akan berpengaruh terhadap keputusan pembelian di toko bagiak pelangi sari Banyuwangi.

5 Hipotesis kelima yang secara teoretik menduga bahwa kepuasan konsumen berpengaruh terhadap keputusan pembeliansecara empirik terbukti signifikan, sehingga $\mathrm{H}_{5}$ diterima. Jadi semakin tinggi kepuasan konsumen akan berpengaruh terhadap keputusan pembelian di toko bagiak pelangi sari Banyuwangi.

\section{Saran}

Kepuasan konsumen yang baik akan meningkatkan personal selling dan kualitas produk yang baik di mata konsumen. Konsumen biasanya memiliki pengetahuan dan waktu yang terbatas pada saat membuat keputusan pembelian Pelangi Sari agar banyak menginformasikan hal-hal yang berhubungan kualitas produk bagiak kepada konsumen, dan menjalin hubungan baik dengan konsumen salah satunya dengan meningkatkan personal selling melalui pelatihan-pelatihan sehingga bisa membentuk motivasi tinggi baik penjual kepada konsumen.

Selain itu peneliti menyarankan agar pelangi sari membangun komunitas online melalui sosial media (seperti whatsup, Line dan twiter) sehingga saluran interaktif dengan konsumen lebih mudah memberikan suatu pesan, menangani keluhan, menjawab keinginantahuan konsumen dan menyampaikan berita baru tentang kue bagiak pelangi sari kepada konsumen.

\section{DAFTAR PUSTAKA}

Bhaskara (2011) dengan judul Customer Relationship Management (Crm) Dan Personal Selling Pengaruhnya Terhadap Kepuasan Konsumen Pada PT Virgo Ekspres Tours \& Travel Manado.

Darmo (2013) judul penelitian pengaruh personal selling \& sales promotion terhadap kepuasan konsumen (studi kasus : jne duta square)

DennyIrawan (2013) “Analisa pengaruh kualitas produk terhadap loyalitas melalui kepuasan sebagai variabel intervening pada konsumen restoran por kee Surabaya" JURNAL MANAJEMEN PEMASARAN Vol. 1, No. 2, (2013) 1-8

Destiana (2015) "Pengaruh Citra Merek dan Kepuasan KonsumenTerhadap Keputusan Pembelian Pada Steak House Kota Bandung".

Edi safni, r (2014) tentang pengaruh personal selling dan kualitas produk terhadap keputusan pembelian. Jurnal Ilmiah Manajemen Kesatuan Vol. 2 No. 1, 2014 pp. 69-78 STIE Kesatuan ISSN 2337 7860

Gaspersz, V. 2008.Total Quality Managament. Jakarta: Penerbit Gramedia Pustaka Utama

Ghozali I. 2005.Aplikasi Analisis Multivariate dengan program SPSS. Semarang (ID): Badan Penerbit Universitas Diponegoro.

Ghozali I. 2008.Structural Equation Modeling Metode Alternatif dengan Partial Least Square. Semarang (ID). Badan Penerbit Universitas Diponegoro.

Herliagiani (2012) jurnal manajemen vol 09 no 4 juli 2012 dengan judul "Pengaruh kualitas produk terhadap keputusan pembelian handphone blackberry

Ika fitria (2011) dengan judul pengaruh kepuasan dan kepercayaan konsumen terhadap keputusan pembelian ulang pada depot air minum tris water Reverse Osmosis System (RO)

Kotler Philip dan Amstrong, 2010, Prinsip-Prinsip Manajemen, Jilid 1 Edisi Tigabelas, Alih Bahasa Oleh Damos Sihombing, MBA., Penerbit Erlangga, Jakarta.

Mulyono (2008) “analisis pengaruh kualitas produk dan kualitas layanan terhadap kepuasan konsumen"

Nur cholis, R (2010) meneliti tentang pengaruh personal selling terhadap keputusan pembelian produk tianshi (Survei pada Tianshi Group Stokis 124 Jln. Pasar Besar 104 Malang) 